\title{
Cost-effectiveness of benign Wirsung duct strictures treatment in chronic pancreatitis
}

\author{
Dariusz Łaski ${ }^{1}$, Stanisław Hać ${ }^{1}$, Iwona Marek ${ }^{2}$, Jarosław Kobiela ${ }^{1}$, Justyna Kostro ${ }^{1}$, Krystian Adrych ${ }^{2}$, Zbigniew Śledziński ${ }^{1}$ \\ ${ }^{1}$ Department of General, Endocrine and Transplant Surgery, Medical University of Gdansk, Gdansk, Poland \\ ${ }^{2}$ Department of Gastroenterology and Hepatology, Medical University of Gdansk, Gdansk, Poland
}

Videosurgery Miniinv 2018; 13 (1): 17-26

DOI: https://doi.org/10.5114/wiitm.2018.72578

\begin{abstract}
Introduction: Chronic pancreatitis (CP) is an important problem for modern medicine, the healthcare system (Poland - NFZ) and the national insurance system (Poland - ZUS). The chronic nature of the disease, the lack of targeted treatment and the low mortality rate lead to an accumulation of patients who demand expensive treatment, both conservative and invasive. Rising costs in health care are forcing the need for a more cost-effective method of treatment. Aim: The primary aim of this study was to perform a retrospective calculation of costs in both surgical and endoscopic treatment, hospital stay, healthcare, and public insurance of patients suffering from chronic pancreatitis. Parallel quality of life analysis was performed. It was possible to develop a cost-effective therapeutic algorithm for patients with an uncomplicated stricture of Wirsung's duct within the Polish health care system.

Results: In Poland, the hospital costs of endoscopic treatment of patients with chronic pancreatitis were higher than those of the surgical treatment group despite both resulting in a similar life quality.

Conclusions: From a cost-effectiveness perspective, it was shown that surgical intervention is a more cost-effective therapy than endotherapy. Furthermore, patients with benign stricture of the main pancreatic duct in chronic pancreatitis should not be treated with endotherapy for longer than 12 months.
\end{abstract}

Key words: chronic pancreatitis, endotherapy, surgical drainage procedures, Wirsung duct stricture, cost-effectiveness.

\section{Introduction}

Chronic pancreatitis (CP) is a major concern from the point of view of modern medicine, the health care system and the social security system. The Polish population has approximately 2,000 new cases of CP every year [1, 2], mostly among men at the peak of productive age (35-50 years), in most cases patients smoking and abusing alcohol [3-5]. The chronic nature of the disease and low mortality lead to the accumulation of patients requiring expensive treatment, both conservative and invasive (endotherapy, surgery) [6]. One of the most important clinical problems of CP is that modern medicine has no causative treatment of CP, since both endotherapy and surgical treatments are only symptomatic treatments [7].

The European Society of Gastrointestinal Endoscopy (ESGE) issued a recommendation (Level B) that endoscopic treatment should be the first line treatment in uncomplicated cases of chronic pancreatitis with pain syndrome. A high efficacy of endoscopic drainage has been shown (75-94\%) [8-14]. In the case of an unsatisfactory effect further treatment should be discussed by a multidisciplinary team (endoscopist, surgeon and radiologist). In this situation, surgical treatment should be considered, especially if the patient can be expected to have little chance of a sustained response to endotherapy [15]. This

\section{Address for correspondence}

Dariusz Łaski MD, PhD, Department of General, Endocrine and Transplant Surgery, Medical University of Gdansk, 17 Smoluchowskiego St, 80-214 Gdańsk, Poland, phone: +48 509538 776, e-mail: dlaski@gumed.edu.pl 
position is also confirmed in the recommendations of the American Society for Gastrointestinal Endoscopy (ASGE) of 2006 [16].

On the basis of those standards $[15,16]$ and also Polish Pancreatic Club recommendations, the wrong conclusion should not be made about the rivalry between endotherapy and surgical treatment of drainage as a method of choice in CP. With these recommendations, it is possible to select patients who will achieve greater benefit from endoscopic than surgical treatment [17].

There are a number of data on surgical and endoscopic treatment of CP and guidelines for conduct. Unfortunately, there are only a few reports of a comparative character for both methods and evaluation of the cost-effectiveness ratio [18-22]. The ratio of treatment costs to the quality of life and the real burden on the health care system associated with surgery and endotherapy is also not known. The author of this paper sees a gap, which was established in connection with the changes in the Polish health care system and the ongoing crisis in the social insurance sector. The operations reforming the health care system in Poland are aimed at optimizing the cost of treatment. In other health systems the monitoring of the treatment in the context of cost efficiency and trying to estimate the cost-effectiveness relationship of two main algorithms in invasive treatment of $\mathrm{CP}$ is introduced. In Poland there is no comprehensive study which would allow one to refer the data to the specificity of the Polish health care system.

\section{Aim}

The scope of the paper is to determine the cost of surgical and endoscopic treatment in patients with chronic pancreatitis, for the hospital, the health system and the social security system in Polish con-

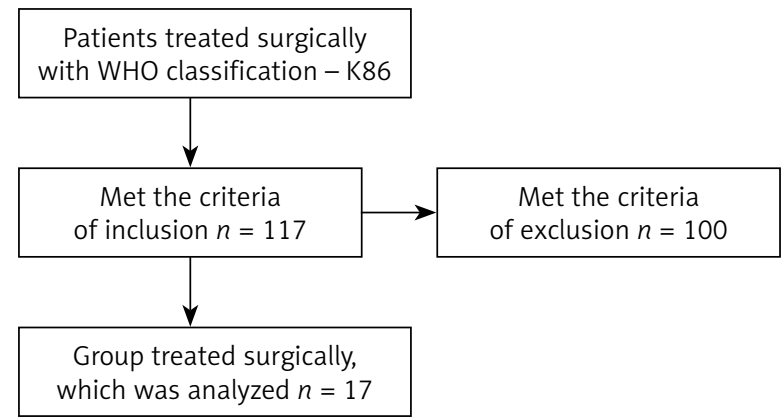

Figure 1. Group treated surgically - selection scheme of the study group, treated surgically ditions. A further aim is to establish an algorithm for dealing with patients with uncomplicated stenosis of the Wirsung duct in the course of CP in the reality of the Polish health care system based on the treatment cost-effectiveness ratio.

\section{Material and methods}

The retrospective study analyzed direct and indirect costs of treatment of patients with $\mathrm{CP}$ hospitalized at the University Clinical Center (UCC). All patients with ICD10-K86 diagnosis and hospitalized in UCC in the years 2006-2011 were checked. In order to select a uniform and homogeneous group the following criteria for inclusion and exclusion from the study were used.

Criteria for inclusion in the analysis: CP - onset of treatment in the years 2006-2011, confirmed diagnosis of CP (history, imaging studies), objectively confirmed Wirsung duct stenosis on CT, ultrasound or endoscopic retrograde cholangiopancreatography (ERCP), confirmation of stenosis during the first session of endotherapy; hospitalization in the Department of Gastroenterology and Hepatology of the Medical University of Gdansk associated with pancreatic endotherapy or at the Department of General, Endocrine and Transplant Surgery, Medical University of Gdansk associated with drainage or drainage-resection surgery (pancreatojejunostomy according to Puestow, Frey or Bern).

Criteria of exclusion: previous surgical procedures on the pancreas; endoscopic or surgical treatment of pancreas outside the center of the trial; suspected tumor of the pancreas; diagnosis of bile duct or duodenal stenosis in the course of CP; age < 18 and $>65$ years (outside of productive age); follow-up period of less than 1 year; previous analgesic surgical treatment (splanchnicectomy, alcohol injection

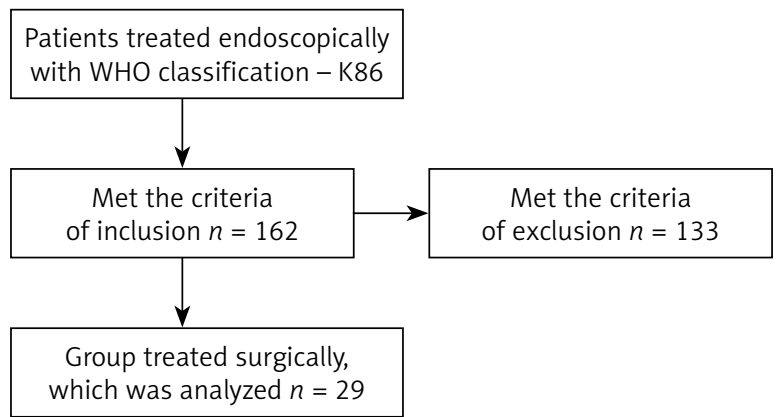

Figure 2. Group treated endoscopically - selection scheme of the study group, treated endoscopically 
into celiac plexus); incomplete documentation - no data for medical costs calculation (Figures 1, 2).

In calculating the direct costs for the hospital, cost of drugs, diagnostics (imaging and invasive), consultations, the cost of the operating theater, anesthesia costs, hospital overhead administrative costs and the final income of the hospital were taken into account.

Analysis of indirect cost was based on an assessment period of sickness absence (only for disease entity - K86) and the number of days of allocated pensions due to sickness incapacity for work (the main cause of incapacity - K86), rehabilitation benefits from social insurance, helplessness allowances from social insurance, unemployment benefits paid by the Labor Offices (LO) and the benefits provided by the Municipal Social Assistance Centers (MSAC), and thus the costs for the social security system, social welfare and labor offices.

The costs incurred by the healthcare system (NFZ) were calculated as the sum of medical procedures. In order to standardize settlements with the National Health Fund (NFZ) the value of the hospital reimbursement point applied in October 2011 was set (direct costs were charged in accordance with the prices in force in the UCC during this period).

Quality of life was assessed after the end of the 3-year follow-up period using three validated tools [23-28]. The form proposed by Bloechle and Izbicki was used [29]. Izbicki score - a factor of Izbicki, EQ5D-5L with EQ-VAS (1990 EuroQol Group. EQ-5D EuroQol Group) [30] and SF-36 (1992 MOS: 36 item Short Form Health Survey RAND Corporation) [31].

For the evaluation of treatment complications a six-level DeOliveira scale was used [32].
In this paper, a "cost of illness (CoL)" analysis was carried out. The cost of disease and cost-effectiveness (CEA) on the basis of direct costs (hospital) and indirect costs (sick leave, pension, reimbursement of medicines, etc.) was summarized with the quality of life determined by the SF-36, EQ-5D and Izbicki score. Data on the costs after the first year of treatment and at the end of the 3-year observation period were compared with the quality of life assessed at the beginning of observation.

\section{Statistical analysis}

In descriptive analyses indicators of the structure, means and standard deviations were used. In comparative analyses Student's $t$-test, the $\chi^{2}$ test and the Mann-Whitney test were used. Analysis of variance was performed using ANOVA and the posthoc Scheffe test. Statistical significance was accepted at $p<0.05$. Statistical analyses were performed using Statistica commercial software.

\section{Results}

\section{Population}

Analyzed groups contained 29 patients treated endoscopically and 17 who underwent surgery. There were no statistically significant differences between groups in demographic structure or disease stage (Tables I, II).

\section{Total hospitalization costs}

Total hospital costs (cost of hospital stay, medical procedure related costs, medications, diagnos-

Table I. Demographic structure and distribution of the etiology of CP in study groups with the level of statistical significance, the odds ratio and 95\% confidence interval

\begin{tabular}{|lccc|}
\hline Parameter & Group treated endoscopically & Group treated surgically & $P$-value \\
\hline Number of patients & 29 & 17 & 0.3 \\
\hline Mean age at start of treatment [years] & $48.7 \pm 10.4$ & $46 \pm 8.8$ & 0.6 \\
\hline Gender M/F & $11 / 18(38 \% / 62 \%)$ & $5 / 12(30 \% / 70 \%)$ & 0.08 \\
\hline Duration of CP before treatment [years] & $5 \pm 5.2$ & $7.5 \pm 4$ & 1.0 \\
\hline BMl at start of treatment & $22.3 \pm 3.5$ & $22.2 \pm 3$ & 0.9 \\
\hline Alcohol etiology & $15(52 \%)$ & $1(53 \%)$ & 0.2 \\
\hline Biliary etiology & $6(21 \%)$ & $7(41 \%)$ & 0.3 \\
\hline Unknown etiology/unspecified & $8(27 \%)$ & 1 & \\
\hline
\end{tabular}


Table II. Comparison of treatment groups in terms of pancreatic insufficiency, pain intensity and consumption of analgesics before treatment

\begin{tabular}{|lccc|}
\hline Parameter (prior to treatment) & Group treated endoscopically & Group treated surgically & $P$-value \\
\hline Diabetes type 3 & $14 \%$ & $35 \%$ & 0.09 \\
\hline Need of insulin therapy & $10 \%$ & $29 \%$ & 0.11 \\
\hline $\begin{array}{l}\text { Need of pancreatic enzyme } \\
\text { supplementation }\end{array}$ & $100 \%$ & $94 \%$ & 0.3 \\
\hline $\begin{array}{l}\text { Daily dose of pancreatic enzyme } \\
\text { [thousands of units] }\end{array}$ & 62.46 & 67.94 & 0.3 \\
\hline Presence of severe pain & $56 \%$ & $86 \%$ & 0.06 \\
\hline $\begin{array}{l}\text { Subjective assessment of pain } \\
\text { VAS score }\end{array}$ & 2.12 & 3.64 & 0.18 \\
\hline $\begin{array}{l}\text { Received amounts of morphine } \\
\text { equivalents }\end{array}$ & 2.24 & 3.43 & 0.18 \\
\hline
\end{tabular}

tics costs, etc.) after the first year of treatment did not differ significantly between the two treatment groups and were $€ 2660$ (10 $470 \mathrm{zt}$ ) for the endotherapy group and $€ 2550$ (10 $050 \mathrm{zt}$ ) for the surgical drainage group ( $p=0.794)$. The cumulative average total cost of the endotherapy group after 3 years of treatment was $€ 4257 \pm 2000$ (16 $773 \pm 7877$ zt (zt = Polish Zloty), while in the surgical group it was $€ 2879 \pm 1288$ (10 $049 \pm 5077 \mathrm{zt})(p=0.002)$. The longitudinal analysis showed a significant cost difference with the duration of treatment in the endoscopic group (ANOVA $p<0.001$ ). The first year of treatment was the most expensive in both groups $(p<0.001)$ compared to the $2^{\text {nd }}$ and $3^{\text {rd }}$ one.

\section{Procedure related costs}

Endotherapy costs were related to a wide range of treatment options and different number of disposable equipment; the cost ranged from $€ 123$ (486 zt) to $€ 719$ (2510 zt) for a single procedure. The average cost of one procedure calculated on the basis of the real costs was $€ 360 \pm 90(1418 \pm 314$ zt). The longitudinal analysis of the endoscopically treated group showed a significant decrease in costs of endotherapy after the first year of observation (ANOVA $p<0.001)$. In the first year of treatment, costs were the highest (ERCP sessions every 3-6 months) and the difference in costs between the 3 observations was significant.

The costs of the operating theater equipment and anesthesia were charged in the surgical drainage procedures group. The average cost was $€ 268$ $\pm 75(1056 \pm 295 \mathrm{zt})$ for a single procedure. Time of operating procedures ranged from $2 \mathrm{~h} 30 \mathrm{~min}$ to $9 \mathrm{~h}$, and amounted to an average of $4 \mathrm{~h} 15 \mathrm{~min} \pm 1 \mathrm{~h}$ $40 \mathrm{~min}$. The total cost of intervention averaged $€ 460$ \pm 175 (1814 \pm 688 zt) per hospitalization.

\section{Other costs}

There were no significant differences between out-of-hospital drug costs in the group treated endoscopically and surgically both after the first year and the end of the 3-year observation period. The costs of laboratory tests in the endoscopically treated group were significantly higher both in the first year of therapy and at the end of the third year of the follow-up $(p<0.05)$. The total cost of diagnostic imaging is statistically significantly lower in the group treated surgically €37 (144 zt) in comparison to patients treated endoscopically $€ 107$ (420 zt).

\section{Number and length of hospitalizations}

The average number of hospitalizations in the group treated endoscopically was higher than in the surgically treated group ( $p<0.001$ for all comparisons) (Table III).

The cumulative number of hospitalization days (Table IV) was statistically significantly lower in the group treated surgically than in the group treated endoscopically, both after the first year of therapy and at the end of the 3-year follow-up.

Longitudinal analysis of the endoscopically treated group showed a statistically significant decrease in the mean number and length of hospi- 
Table III. Average number of hospitalizations in the study groups

\begin{tabular}{|lcc|}
\hline Hospitalization & Group treated endoscopically & Group treated surgically \\
\hline First year of treatment & $2.79 \pm 1.10$ & $1.17 \pm 0.52$ \\
\hline Second year of treatment & $1.73 \pm 0.72$ & No hospitalizations \\
\hline Third year of treatment & $1.44 \pm 0.61$ & No hospitalizations \\
\hline $\begin{array}{l}\text { Mean number of hospitalizations per year } \\
\text { during follow-up }\end{array}$ & $2.08 \pm 0.96$ & $0.53 \pm 0.17$ \\
\hline
\end{tabular}

Table IV. Cumulative average length of hospitalization in both groups

\begin{tabular}{|lccc|}
\hline Variable & \multicolumn{2}{c}{ Average length of hospital stay [days] } & \multirow{2}{*}{$P$-value } \\
\cline { 2 - 3 } & Endoscopic treatment & Surgical treatment & \\
\hline In the first year & $17.90 \pm 11.75$ & $11.47 \pm 7.84$ & 0.049 \\
\hline After 3 years & $25.97 \pm 16.02$ & $11.47 \pm 7.84$ & 0.001 \\
\hline
\end{tabular}

talizations with subsequent years of observation (ANOVA $p<0.001$ ). In the first year of treatment, the number of hospitalizations per patient was the highest $(p<0.001)$ and the stays were the longest $(p<0.001)$.

\section{Complications}

The incidence of method specific complications (endotherapy: post-ERCP pancreatitis or readmission because of exacerbation of CP during endotherapy = 10, surgery: CP exacerbation in post-operative period $n=1$ ) and nonspecific (endotherapy: intra-abdominal infection not related to pancreas $n=2$, urinary tract infections $n=1$, peptic ulcers $=1$, limb ischemia $=1$, surgery: wound infection $n=3$, sub- cutaneous hematoma $n=1$ ) showed no statistically significant differences between the two groups. Also the assessment of the severity of nonspecific complications by the DeOliveira scale did not show significant differences. We observed a statistically higher severity score of specific complications in patients treated endoscopically (Table V).

\section{Quality of life}

Assessment of global quality of life assessed by the EQ-5D questionnaire showed no significant differences between the two groups. The results of the analysis of the EQ-5D VAS questionnaire showed significantly higher satisfaction with the health status in patients treated surgically.

Table V. Mean number and DeOliveira score severity method specific and nonspecific complications per hospitalization in first year and after 3 years of treatment

\begin{tabular}{|c|c|c|c|c|}
\hline \multirow[t]{2}{*}{ Complications - DeOliveira Score } & & \multicolumn{2}{|c|}{ Mean DeOliveira Score } & \multirow[t]{2}{*}{$P$-value } \\
\hline & & Endotherapy & Surgical treatment & \\
\hline \multirow{2}{*}{$\begin{array}{l}\text { Number of nonspecific complications } \\
\text { per hospitalization }\end{array}$} & $1^{\text {st }}$ year & $0.14 \pm 0.44$ & $0.24 \pm 0.44$ & 0.472 \\
\hline & After 3 years & $0.17 \pm 0.65$ & $0.24 \pm 0.47$ & 0.654 \\
\hline \multirow{2}{*}{$\begin{array}{l}\text { Number of method specific complications } \\
\text { per hospitalization }\end{array}$} & $1^{\text {st }}$ year & $0.28 \pm 0.65$ & $0.06 \pm 0.24$ & 0.191 \\
\hline & After 3 years & $0.28 \pm 0.19$ & $0.06 \pm 0.65$ & 0.191 \\
\hline \multirow{2}{*}{$\begin{array}{l}\text { DeOliveira score of nonspecific complications } \\
\text { per hospitalization }\end{array}$} & $1^{\text {st }}$ year & $0.17 \pm 0.60$ & $0.35 \pm 0.79$ & 0.386 \\
\hline & After 3 years & $0.17 \pm 0.39$ & $0.35 \pm 0.60$ & 0.386 \\
\hline \multirow{2}{*}{$\begin{array}{l}\text { DeOliveira score of method specific complications } \\
\text { per hospitalization }\end{array}$} & $1^{\text {st }}$ year & $1.02 \pm 1.00$ & $0.18 \pm 0.53$ & $<0.001$ \\
\hline & After 3 years & $1.74 \pm 1.68$ & $0.18 \pm 1.68$ & $<0.001$ \\
\hline
\end{tabular}


Between the groups treated endoscopically and surgically there was no significant difference in the Izbicki score.

The two treatment groups did not differ significantly in terms of the summary index of physical health. Statistical analysis of the summary index of mental health (MCS) and its components did not detect significant differences between the two study groups.

\section{Treatment cost-effectiveness}

The cost of a potential increase of pain treatment quality based on the questionnaire EQ-5D VAS value by $1 \%$ for the group treated endoscopically after 3 years of follow-up was $€ 83$ (328 zt). In the surgically treated group, this cost was $€ 37$ (145 zt) (Figure 3).

The cost of a potential increase of the questionnaire EQ-5D value by $1 \%$ for the group treated endoscopically after 3 years of follow-up was $€ 63$ ( $247 \mathrm{zt}$ ). In the surgically treated group the cost was $€ 31$ (123 zt) (Figure 4).

The cost of a potential decrease in the value of Izbicki's factor by $1 \%$ for the group treated endoscopically after 3 years of follow-up was $€ 156$ $(613 \mathrm{zt})$. In the surgically treated group the cost was $€ 110$ (436 zt) (Figure 5).

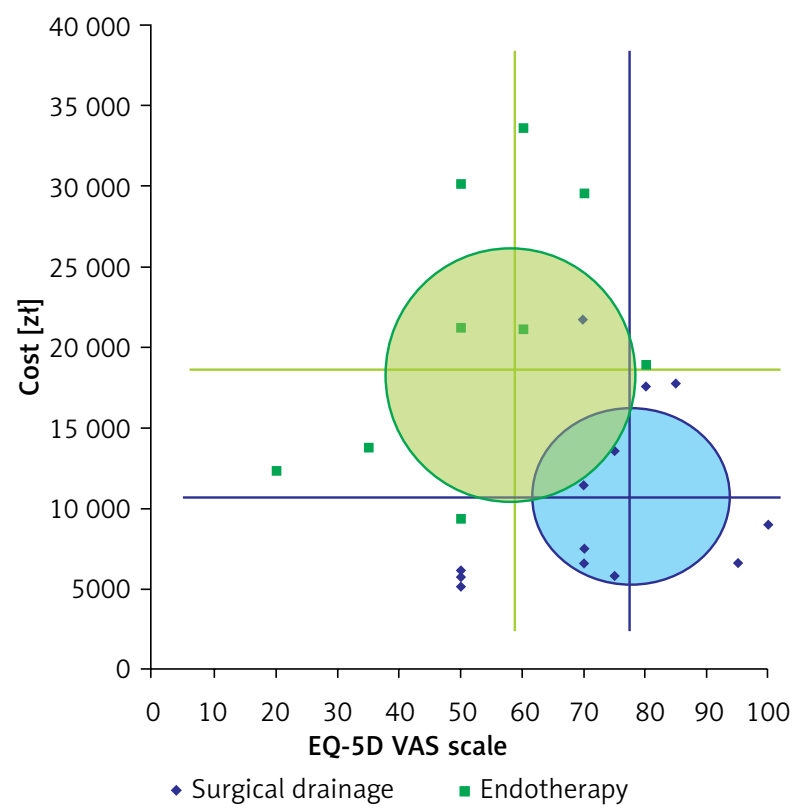

Figure 3. Accumulated cost to quality of life (EQ5D VAS scale) after 3 years of follow-up in both study groups
The cost of a potential increase in the value of the SF 36 PCS factor by $1 \%$ of the group treated endoscopically after 3 years of follow-up was $€ 72$ (286 zt). In the surgically treated group, the cost was $€ 36$ (143 zt) (Figure 6).

\section{Health care system costs}

From the perspective of the 3-year follow-up surgical treatment generates an income for the hospital at approx. $40 \%$ of the sum appraised by the National Health Fund (NFZ), while the endoscopic treatment gives an income of $20 \%$ of the given amount. The difference reaches the threshold of statistical significance $(p=0.042)$. The group treated endoscopically receives significantly higher income from the National Health Fund compared to the group treated surgically, but with significantly higher hospital costs.

The cost of the surgical procedure from the perspective of the payer (NFZ) was after the first year significantly higher. After a 3-year observation period the expense borne by the NFZ was significantly higher in the group treated endoscopically. After taking into account the cost of drug reimbursement (higher in the surgical group, because in Poland patients after any kind of pancreatic tissue resection have full supplementary payment for pancreatic

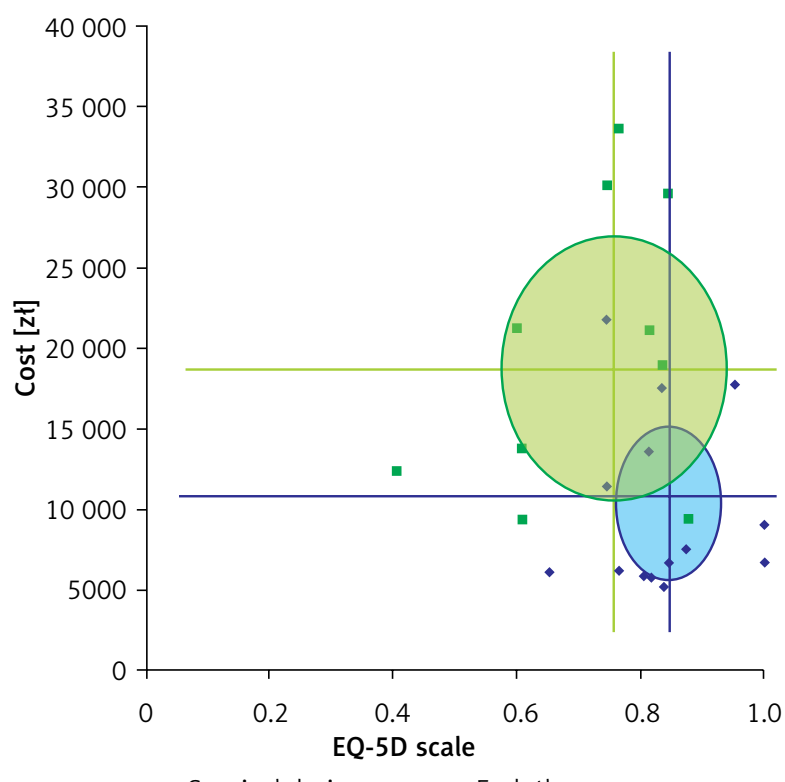

- Surgical drainage $\quad$ Endotherapy

Figure 4. Accumulated cost to quality of life (EQ-5D scale) after 3 years of follow-up in both groups 


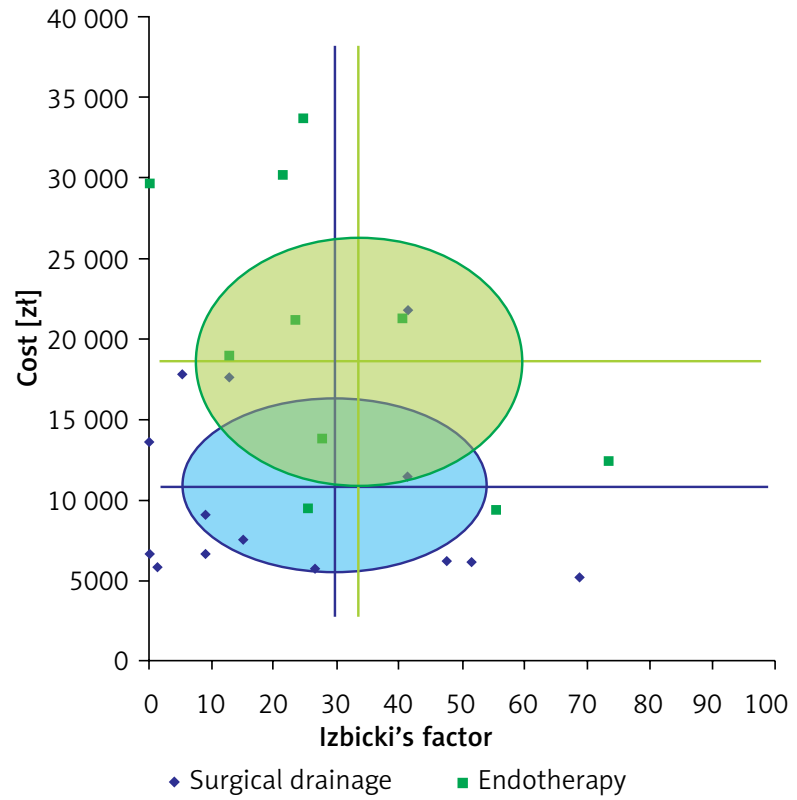

Figure 5. Dependence of the accumulated cost to quality of life (Izbicki's factor) after 3 years of follow-up in both study groups

enzymes supplementation, but after endotherapy patients have to cover this expense), the difference between the study groups was no longer significantly different.

Patients undergoing drainage procedures rarely took any pensions due to inability to work, slightly more often used the help given by Municipal Social Assistance Centers (MSAC) and received an unemployment allowance, and also had lower sick leave absence (113.25 vs. 57.33 days), but none of the differences reached the level of statistical significance. The cumulative cost of all social benefits in the 3-year observation period was lower in patients treated surgically than in patients treated endoscopically (€2500 vs. €4050; 9852 zł vs. 15954 zt, $p=$ 0.151 ). This relationship does not reach statistical significance.

\section{Discussion}

With limited funds for health care and year-toyear shrinkage of the Social Insurance Institution budget, CP is becoming a serious socioeconomic problem. Studies have shown that the percentage of patients with CP treated invasively, unable to work, has increased with time from $6 \%$ to $40 \%$ and in conservative treatment exceeds 50\% [33-35]. Similarly, in this study, the proportion of people unable to

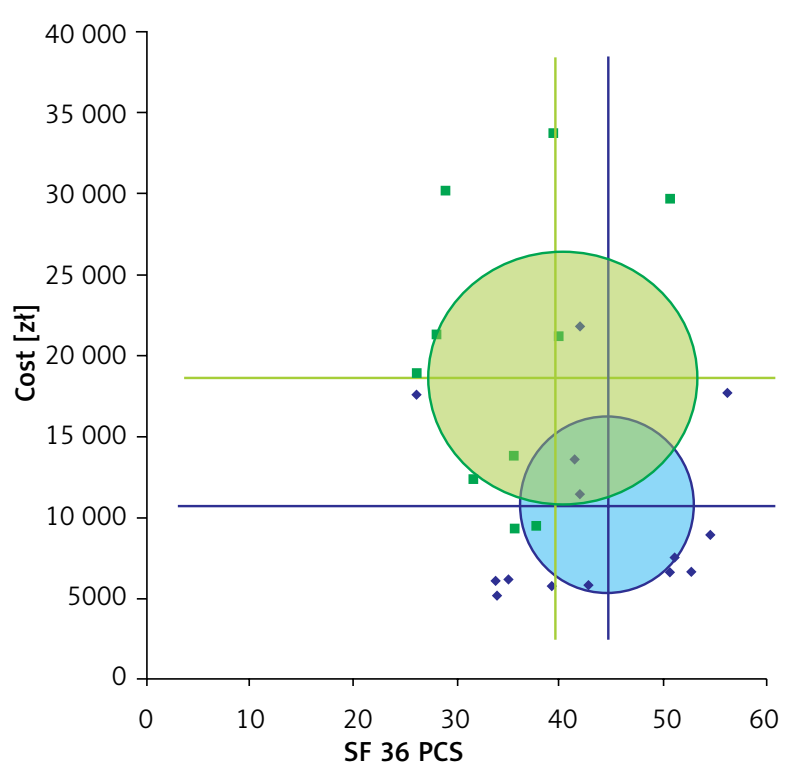

- Surgical drainage - Endotherapy

Figure 6. Dependence of the accumulated cost to quality of life (SF 36 PCS) after 3 years of follow-up in both study groups

work was more than $30 \%$. The majority (70-90\%) of patients were given social benefits (permanently or temporarily) due to illnesses of various kinds. Effectiveness of endotherapy has already been proved, but prolonged endotherapy in chronic pancreatitis is still under discussion [36-38]. In Japanese studies hospital costs, number and length of hospitalizations associated with endotherapy and surgical treatment (mainly Frey operations) were compared [22]. The study was conducted on two study groups of 34 patients. During the first year of follow-up Hirota et al. noted that the cost-effectiveness of treating patients surgically and by "short implantation" (end of treatment until one year) do not differ from each other. The group which required prolonged endotherapy, already during the first year of treatment showed higher medical costs, and longer and more numerous hospitalizations. Hence, in the case where due to the clinical picture the endotherapy extended over 1 year, a decision on the choice of treatment that is more favorable financially - in this case surgery - should be made [22]. In this study, the total cost incurred by the hospital in the first year of treatment, both surgical and endotherapy, did not differ significantly. Patients treated with endotherapy were sent to the hospital significantly more often $(p<0.05)$, and their total hospitalization was 
longer $(p<0.05)$. The lack of difference is a result of the significantly higher cost of staying on a surgical ward. Therefore, even though the annual amount of days of hospitalization of patients treated with surgery is lower, the cost is similar to the group treated endoscopically. Longer hospital stay in the endotherapy group may be caused by readmissions because of exacerbations of CP during endotherapy, and if we consider the small number of analyzed cases it may influence the cumulative length of hospitalization. It is worth mentioning that the outlay of the Japanese health care system, although proportional to the Polish one, was 4 times higher (€2657 vs. €12 156 (10 467 zt vs. 47894 zt) for the endotherapy group and $€ 2550$ vs. $€ 8525$ (100 49 zt vs. 33588 zt) for the surgical drainage group). It is similar as regards the number and length of hospitalization. It follows that both the treatment regimen and average costs differ from Polish conditions and cannot be directly transferred to our situation. The strategy of treatment, hospitalization time and interval between hospitalizations in Polish conditions are determined not only by medical grounds, but also the principles of the financing of medical services by the National Health Fund, which complicates a fair comparison of treatment strategies in other health care systems.

The work of Laramée et al. [19] based on a randomized clinical trial of Cahen et al. compares the cost of endoscopic and surgical treatment from the point of view of the British health system (NHS UK) $[20,21]$. The work was commissioned for the needs of the National Institute for Health and Care Excellence (NICE) in order to create an analysis based on the cost effectiveness in treatment of $\mathrm{CP}$ in the UK. After taking into account the quality of life Laramée et al. obtained a statistically significant favorable cost-effectiveness ratio for surgical treatment in comparison to endotherapy for both the 2- and 6-year follow-up period. Unit costs of a surgical procedure, as well as the percentage of complications, which is associated with expensive treatment and loss of quality adjusted life years (QALYs), are found to be significantly lower than the total cost and the loss of QALYs in multiple endoscopic sessions [19]. Similarly, in this analysis, the potential costs associated with increased quality of life, irrespective of the assessed scale, were higher in the endotherapy group, wherein the difference between the group treated surgically and the group treated endoscopically increased with time. Laramée et al. did not take into account the cost of post-hospital care, the decline in productivity and periods of incapacity to work, recognizing that with a high degree of probability both parameters are favorable for the group treated surgically, especially in the long-term follow-up.

Despite minor differences in the present results and significant differences in medical costs between Poland, Japan and the UK, the same conclusion holds as regards higher medical costs of endotherapy unless it is extended over a year. Moreover, in the study of Cahen et al., during a long (6-year) observation period, more than half of patients with prolonged endotherapy treatment underwent a drainage procedure; however, the effectiveness of the treatment in this case was much lower. The author explained this as being due to a late operative intervention and an increase in irreversible changes of the pancreas [20].

Critically looking at these studies, especially those evaluating the financial performance, we note that they cannot be easily transferred to Polish conditions. Due to different valuation of the procedures and slightly different methods of calculating direct costs, studies from abroad should be treated only as an indicator of contemporary trends in the treatment of CP. Prior to the use of applications in clinical practice in Poland, further studies are needed in local realities. This work extends so far analyzed direct costs by the analysis of the costs incurred by the National Health Fund and the Social Insurance Institution.

For the payer (NFZ) it is favorable and statistically significantly cheaper to refund the endoscopic procedures in the first year of treatment, but after 2 years of treatment costs of hospital procedures are equalized, to become lower for the surgical group after 3 years of follow-up. However, when considering drug reimbursement, which takes on different principles for both groups, it turns out that from the 3-year perspective there is no statistically significant difference for NFZ, which is refunded by the therapeutic algorithm. For comparison, in the UK the amount associated with the treatment of pancreatic exocrine insufficiency is comparable for both groups, which results from the nature of the specific health care system [19]. Unfortunately, there is a lack of papers comparing that specific problem from the point of view of the health care system.

Besides the epidemiological references according to frequency of incapacity to work, there are no publications evaluating the comparative costs associat- 
ed with sickness absence and incapacity for work in both therapeutic algorithms. In that study, no significant differences in terms of social benefits were found, perhaps because of the small number of participants in groups. There are apparent trends that due to the large standard deviations do not reach the threshold of statistical significance. It seems that the number of days off sick and thus the cost for the Social Insurance Institution is lower in the surgically treated group. There is no difference in the amount of paid disability benefits because of the incapacity to work and other social benefits.

\section{Conclusions}

The total medical cost is significantly lower in the surgically treated group in the 3-year follow-up period. In the analysis of the quality of life, pain as the main symptom of CP does not differentiate the two populations studied. Other factors of QoL do not give a clear conclusion, so the parameter determining the ultimate cost-effectiveness ratio is primarily the total medical cost. It follows that in patients in whom the endotherapy extends, exhibits an unsatisfactory efficacy or the chances of success are low, 12 months after the onset of symptoms a multidisciplinary team should be consulted and the surgical treatment option should be considered. In this analysis, we note that both for the health system and social security in Poland with a 3-year follow-up period, there are no statistically significant differences that would prefer one of these methods.

\section{Conflict of interest}

The authors declare no conflict of interest.

\section{References}

1. Dzieniaszewski J, Jarosz M, Ciok J. Chronic pancreatits in Warsaw. Mater Med Pol 1990; 22: 202-4.

2. Gąsiorowska A, Małecka-Panas E. Diagnostyka i leczenie przewlektego zapalenia trzustki. Przew Lek 2007; 1: 76-86.

3. Talamini G, Bassi C, Falconi M, et al. Cigarette smoking: an independent risk factor in alcoholic pancreatitis. Pancreas 1996; 12: 131-7.

4. Ryu JK, Lee JK, Kim YT, et al. Korean Multicenter Study Group on Chronic Pancreatitis. Clinical features of chronic pancreatitis in Korea: a multicenter nationwide study. Digestion 2005; 72: 207-11.

5. Dite P, Ruzicka M, Zboril V, et al. A prospective, randomized trial comparing endoscopic and surgical therapy for chronic pancreatitis. Endoscopy 2003; 35: 553-8.
6. Spanier BW, Dijkgraaf MG, Bruno MJ. Trends and forecasts of hospital admissions for acute and chronic pancreatitis in the Netherlands. Eur J Gastroenterol Hepatol 2008; 20: 653-8.

7. Domżał D, Talar-Wojnarowska R, Woźniak B, et al. The usefulness of endoscopic retrograde cholangiopancreatography in treatment of patients with chronic pancreatitis. Prz Gastroenterol 2009; 4: 193-8.

8. Cremer M, Deviere J, Delhaye M, et al. Stenting in severe chronic pancreatitis: results of medium-term follow-up in 76 patients. Endoscopy 1991; 23: 171-6.

9. Binmoeller KF, Jue P, Seifert $H$, et al. Endoscopic pancreatic stent drainage in chronic pancreatitis and a dominant stricture: long-term results. Endoscopy 1995; 27: 638-44.

10. Smits ME, Badiga SM, Rauws EAJ, et al. Long-term results of pancreatic stents in chronic pancreatitis. Gastrointest Endosc 1995; 42: 461-7.

11. Ponchon T, Bory R, Hedelius F, et al. Endoscopic stenting for pain relief in chronic pancreatitis: results of a standardized protocol. Gastrointest Endosc 1995; 42: 452-6.

12. Topazian M, Aslanian H, Andersen D. Outcome following endoscopic stenting of pancreatic duct strictures in chronic pancreatitis. J Clin Gastroenterol 2005; 39: 908-11.

13. Morgan DE, Smith JK, Hawkins K, et al. Endoscopic stent therapy in advanced chronic pancreatitis: relationships between ductal changes, clinical response, and stent patency. Am J Gastroenterol 2003; 98: 821-6.

14. Smoczyński M, Dubowik M, Marek I, et al. Endoskopowy drenaż trzustkowych zbiorników płynowych. Gastroenterol Pol 2004; 11: 413-20.

15. Dumonceau JM, Delhaye M, Tringali A, et al. Endoscopic treatment of chronic pancreatitis: European Society of Gastrointestinal Endoscopy (ESGE) Clinical Guideline. Endoscopy 2012; 44: 784-800.

16. Adler DG, Lichtenstein D, Baron TH, et al. The role of endoscopy in patients with chronic pancreatitis. Gastrointest Endosc 2006; 63: 933-7.

17. Żuk K, Czkwianianc E, Degowska M, et al. Zalecenia diagnostyczne i terapeutyczne w przewlekłym zapaleniu trzustki. Rekomendacje Grupy Roboczej Konsultanta Krajowego w dziedzinie Gastroenterologii i Polskiego Klubu Trzustkowego. Prz Gastroenterol 2011; 6: 339-52.

18. Howard TJ, Jones JW, Sherman S, et al. Impact of pancreatic head resection on direct medical costs in patients with chronic pancreatitis. Ann Surg 2001; 234: 661-7.

19. Laramée P, Wonderling D, Cahen DL, et al. Trial-based cost-effectiveness analysis comparing surgical and endoscopic drainage in patients with obstructive chronic pancreatitis. BMJ Open 2013; 3(9).

20. Cahen DL, Gouma DJ, Laramee P, et al. Long-term outcomes of endoscopic vs surgical drainage of the pancreatic duct in patients with chronic pancreatitis. Gastroenterology 2011; 141: 1690-5.

21. Cahen DL, Gouma DJ, Nio Y, et al. Endoscopic versus surgical grainage of pancreatic duct in chronic pancreatitis. N Engl J Med 2007; 356: 676-84.

22. Hirota M, Asakura T, Kanno A, et al. Long-period pancreatic stenting for painful chronic calcified pancreatits required high- 
er medical costs and frequent hospitalizations compared with surgery. Pancreas 2011; 40: 946-50.

23. Ware JE. SF-36 health survey update. Spine 2000; 25: 3130-9.

24. Rabin R, de Charro F. EQ-5D: a measure of health status from the EuroQol Group. Ann Med 2001; 33: 337-43.

25. Broome AH, Eisen GM, Harland RC, et al. Quality of life after treatment for pancreatitis. Ann Surg 1996; 223: 665-70.

26. Pezzilli R, Bini L, Fantini L, et al. Quality of life in chronic pancreatitis. World J Gastroenterol 2006; 39: 6249-51.

27. Pezzilli R, Morselli Labate AM, Ceciliato R, et al. Quality of life in patients with chronic pancreatitis. Dig Liver Dis 2005; 37: 181-9.

28. Devlin NJ, Krabbe PF. The development of new research methods for the valuation of EQ-5D-5L. Eur J Health Econ 2013; 14: S1-3.

29. Bloechle C, Izbicki JR, Knoefel WT, et al. Quality of life in chronic pancreatitis - results after duodenum-preserving resection of the head of the pancreas. Pancreas 1995; 11: 77-85.

30. Herdman M, Gudex C, Lloyd A, et al. Development and preliminary testing of the new five-level version of EQ-5D (EQ-5D-5L). Qual Life Res 2011; 20: 1727-36.

31. Ware JE, Sherbourne CD. The MOS 36-Item Short-Form Health Survey (SF-36): conceptual framwork and item selection. Med Care 1992; 30: 473-83.

32. DeOliveira ML, Winter JM, Schafer M, et al. Assessment of complications after pancreatic surgery: a novel grading system applied to 633 patients undergoing pancreatoduodenectomy. Ann Surg 2006; 244: 931-9.

33. Lankisch PG, Assmus C, Maisonneuve P, et al. Epidemiology of pancreatic diseases in Lüneburg County. A study in a defined German population. Pancreatology 2002; 2: 469-77.

34. Gastard J, Joubaud F, Farbos T, et al. Etiology and course of primary chronic pancreatitis in Western France. Digestion 1973; 9: 416-28.

35. Andersen BN, Pedersen NT, Scheel J, Worning $H$. Incidence of alcoholic chronic pancreatitis in Copenhagen. Scand J Gastroenterol 1982; 17: 247-52.

36. Jagielski M, Smoczyński M, Adrych K. Transpapillary drainage of pancreatic parenchymal necrosis. Videosurgery Miniinv 2015; 10: 491-4.

37. Smoczyński $M$, Jagielski $M$, Jabłońska $A$, et al. Transpapillary drainage of walled-off pancreatic necrosis - a single center experience. Videosurgery Miniinv 2015; 10: 527-33.

38. Smoczyński M, Jagielski M, Jabłońska A, et al. Endoscopic necrosectomy under fluoroscopic guidance - a single center experience. Videosurgery Miniinv 2015; 10: 237-43.

Received: 18.05.2017, accepted: 29.10.2017. 